\title{
The role of single instillation chemotherapy in patients who receive subsequent bacillus Calmette-Guérin: A retrospective single centre study, and systematic review of the literature
}

\author{
Kazuhiro Matsumoto, MD; Tatsuo Gondo, MD, PhD; Nozomi Hayakawa, MD; Takahiro Maeda, MD; \\ Akiharu Ninomiya, MD; So Nakamura, MD, PhD
}

Tokyo Saiseikai Central Hospital, Department of Urology, Minato-ku, Tokyo, Japan

Cite as: Can Urol Assoc J 2015;9(7-8):E411-6. http://dx.doi.org/10.5489/cuaj.2818 Published online July 17, 2015.

\section{Abstract}

Introduction: This retrospective study was undertaken to evaluate the combined effect of immediate intravesical chemotherapy and subsequent bacillus Calmette-Guérin (BCG) therapy.

Methods: The study population consisted of 207 intermediate- or high-risk patients with non-muscle invasive bladder cancer who underwent an induction course of BCG between 1993 and 2007. We introduced single immediate instillation of $50 \mathrm{mg}$ epirubicin for all cases in 2004, and thus earlier cases could be considered as historical controls. The primary endpoint was recurrence-free survival (RFS). For cumulative analysis, we systematically reviewed studies indexed in databases. Including ours, the records of 856 patients from a total of 7 studies, including ours, were finally analyzed.

Results: In our cohort, the 5-year RFS in patients who received the combination therapy was $66.2 \%$, compared to $55.2 \%$ in the BCG alone group $(p=0.149)$. Multivariate analysis on tumour recurrence showed that patients with the combination therapy had a hazard ratio $(H R)$ of $0.74(p=0.189)$. A subsequent literature review revealed that RFS rates in the combination groups were higher than those in the corresponding BCG alone groups in $4 / 7$ studies $(p=0.02-0.15)$, and lower in 1 study $(p=0.51)$. We identified 5 studies which examined a HR for combination therapy, and performed a cumulative analysis. Adding a single chemo-instillation prior to BCG resulted in a significant reduction in tumour recurrence (summary HR 0.69, $p=0.010$ ).

Conclusions: Our analysis suggested that the combination of single chemo-instillation with subsequent BCG therapy exhibited an additive effect against potential tumour recurrence.

\section{Introduction}

Intermediate- or high-risk non-muscle invasive bladder cancers (NMIBC) with stage Ta or T1 and/or carcinoma in situ (CIS) are usually treated by transurethral bladder tumour resection (TUR-BT) and an adjuvant course of chemotherapy or bacillus Calmette-Guérin (BCG) immunotherapy to pre- vent recurrence. Based on the results of several randomized trials, it has become obvious that intravesical BCG instillation with or without maintenance therapy is effective in treating intermediate- or high-risk NMIBC; it is superior to other intravesical agents to prevent tumour recurrence. ${ }^{1-5}$

To date, multiple clinical trials have focused on the efficacy of single immediate instillation of chemotherapeutic agents. ${ }^{6}$ However, the role of immediate perioperative chemotherapy for intermediate- and high-risk tumors has remained unclear and some urologists do not use perioperative chemotherapy ${ }^{7}$ because patients in this category should receive a further course of adjuvant chemotherapy or BCG in line with clinical guidelines. ${ }^{8-10}$ If an early single dose instillation does not improve BCG efficacy, it should be limited to low-risk or some intermediate-risk tumours that would not require additional BCG therapy. However, if clinical benefit could be rendered by a single dose instillation prior to BCG therapy, it would be advisable in all NMIBC. To address this issue, we evaluated the role of single instillation chemotherapy in patients who were due to receive subsequent BCG therapy, and also performed a systematic review of other similar studies.

\section{Methods}

We retrospectively reviewed 207 BCG naive patients with intermediate- or high-risk NMIBC who underwent an induction course (6 times) of BCG between 1993 and 2007. We introduced single immediate instillation of $50 \mathrm{mg}$ epirubicin following TUR-BT for all cases in 2004, and thus earlier cases could be considered as historical controls. Neither photodynamic diagnosis nor narrow band imaging was used, and no patient in this study cohort received a second TUR. BCG treatment at a dose of 40.5-81 mg (Connaught strain), or 40-80 mg (Tokyo 172 strain) was begun 4 to 5 weeks after TUR-BT, and continued weekly for 6 weeks. These cases were routinely assessed by urine cytology and cystoscopy every 3 months for the first 2 years after TUR-BT, and every 
6 months thereafter. The starting point of this study was the timing of TUR-BT, and the endpoint was tumour recurrence. The end of the observation period was December 2013.

To complete our analysis and comparison, we identified studies that compared patients receiving any intravesical chemotherapy (first instillation was within 24 hours following TUR-BT) plus subsequent BCG with the control patients treated with BCG alone. We used the following medical subject heading terms and or text words: "bladder cancer, single, bcg;" "bladder cancer, immediate, bcg;" and "bladder cancer, perioperative, bcg," and MEDLINE, Web of Science, and EMBASE were searched (from inception to December 2013) for English-language studies. Prospective and retrospective studies were eligible for analysis. We also reviewed the reference lists of the identified publications and relevant review articles for additional pertinent studies. All searches were conducted independently (KM, TG). The results were compared, and any questions or discrepancies were resolved through iteration and consensus.

The difference in continuous measurements between groups was analyzed using the Mann-Whitney test. The chisquare test was used to analyze the difference in numbers of patients between two groups. Recurrence-free survival (RFS) curves were constructed using the Kaplan-Meier method, and were compared with the log-lank test. Univariate and multivariate hazard ratio $(H R)$ analyses were performed using the Cox proportional hazards model. Summary HR estimates were calculated using the random-effects method. ${ }^{11}$ Inter-study heterogeneity was tested using the Cochran $Q$ statistic (chi-square value), with the significance level set at $\mathrm{p}<0.10$, and was quantified using the $I^{2}$ statistic, where a value of $50 \%$ or greater indicated substantial heterogeneity. ${ }^{12}$ Publication bias was assessed by constructing a funnel plot. ${ }^{13}$

All procedures and all subsequent revisions complied with the Declaration of Helsinki 1964. The protocol was approved by the Institutional Review Board at our centre.

\section{Results}

In our study cohort, a total of 97 patients received perioperative epirubicin in conjunction with an induction course of BCG, and 110 received BCG alone (Table 1). The mean follow-up was 3.8 years (median 3.8) in the combination (single immediate epirubicin and BCG) group, and 5.4 years (median 3.4) in the BCG alone group. There was a significant difference in the mean age between groups, and concomitant CIS was more frequently observed in the combination group. There were no significant differences between groups with respect to the other factors.

Recurrence was observed in $34.0 \%$ (33 of 97) of the combination group, and $49.1 \%$ (54/110) of the BCG alone group. The 5-year RFS in patients who received the com-

\begin{tabular}{|c|c|c|c|c|}
\hline & & $\begin{array}{c}\text { Perioperative } \\
\text { epirubicin + } \\
\text { BCG }(n=97)\end{array}$ & $\begin{array}{c}\text { BCG alone } \\
(n=110)\end{array}$ & $\begin{array}{c}p \\
\text { value }\end{array}$ \\
\hline Age & mean (SD) & $70.2 \pm 11.0$ & $66.4 \pm 12.0$ & 0.014 \\
\hline Gender & male/female & $83 / 14$ & $88 / 22$ & 0.292 \\
\hline \multirow[t]{2}{*}{ Risk group } & High- & $63(64.9 \%)$ & 72 (65.5\%) & 0.939 \\
\hline & Intermediate- & $34(35.1 \%)$ & $38(34.5 \%)$ & \\
\hline \multirow[t]{2}{*}{ Past history } & Primary & $63(64.9 \%)$ & $83(75.5 \%)$ & 0.098 \\
\hline & Recurrent & $34(35.1 \%)$ & 27 (24.5\%) & \\
\hline \multirow[t]{2}{*}{ Multiplicity } & Solitary & $42(43.3 \%)$ & $42(38.2 \%)$ & 0.454 \\
\hline & Multiple & 55 (56.7\%) & $68(61.8 \%)$ & \\
\hline \multirow[t]{2}{*}{$\begin{array}{l}\text { Stage at } \\
\text { TUR }\end{array}$} & $\mathrm{Ta}$ & $53(54.6 \%)$ & 57 (51.8\%) & 0.685 \\
\hline & $\mathrm{T} 1$ & $44(45.4 \%)$ & $53(48.2 \%)$ & \\
\hline \multirow[t]{2}{*}{ Grade } & G1/G2 & 58 (59.8\%) & $64(58.2 \%)$ & 0.814 \\
\hline & G3 & $39(40.2 \%)$ & $46(41.8 \%)$ & \\
\hline \multirow[t]{2}{*}{$\begin{array}{l}\text { Concomitant } \\
\mathrm{CIS}\end{array}$} & Yes & $32(33.0 \%)$ & $22(20.0 \%)$ & 0.034 \\
\hline & No & $65(67.0 \%)$ & $88(80.0 \%)$ & \\
\hline
\end{tabular}

The pathological high-risk cases were defined as tumors with G3 and/or pT1 and/or concomitant CIS. Multiple and/or recurrent G1-2 pTa tumors were regarded as intermediate risk tumours.

BCG: bacillus Calmette-Guérin; SD: standard deviation; TUR: transurethral resection; CIS: carcinoma in situ.

bination therapy was $66.2 \%$, compared to $55.2 \%$ in their counterparts, although this difference was not statistically significant ( $p=0.149$ ) (Fig. 1). Multivariate analysis, controlling for standard clinicopathological risk factors (past history, multiplicity, stage, grade, concomitant CIS), ${ }^{8-10}$ demonstrated that the combination group had a recurrence risk of 0.74 (95\% confidence interval (Cl) $0.47-1.16$ ), but this was not indicated statistically as an independent prognostic factor $(p=0.189)$ (Table 2).

Next, we carried out a literature search for cases published in English to examine the difference in RFS between the combination therapy (immediate chemotherapy plus BCG) group and the BCG alone group (Fig. 2). Six articles ultimately met our predefined inclusion criteria, and were included in the final analyses. ${ }^{14-19}$ Including our retrospective study, this provided a total of 856 cases ( 7 studies) for systematic review (Table 3 ).

RFS rates in the combination groups were higher than those in the corresponding BCG alone groups in 4/7 studies $(p=0.02-0.15)$, and lower in one study $(p=0.51)$. Two studies did not report HR data that were valid for inclusion, and the cumulative analysis of HR was performed using the results of 5 studies (Fig. 3a). All but one individual study showed HR estimates below 1.0, although none of the estimates were statistically significant $(p>0.05)$. The summary HR for tumour recurrence comparing subjects with and without immediate perioperative chemotherapy was 0.69 (95\% Cl 0.52-0.92, $p=0.010)$. Between-study heterogeneity might not be significant $\left(p=0.62 ; r^{2}=0 \%\right)$. Visual inspec- 


\begin{tabular}{|c|c|c|c|c|}
\hline & \multicolumn{2}{|c|}{ Univariate analysis } & \multicolumn{2}{|c|}{ Multivariate analysis } \\
\hline & $\begin{array}{c}p \\
\text { value }\end{array}$ & $\begin{array}{c}\mathrm{HR} \\
(95 \% \mathrm{Cl})\end{array}$ & $\begin{array}{c}p \\
\text { value }\end{array}$ & $\begin{array}{c}\mathrm{HR} \\
(95 \% \mathrm{Cl})\end{array}$ \\
\hline $\begin{array}{l}\text { Age as continuous } \\
\text { variable }\end{array}$ & 0.560 & $\begin{array}{c}0.99 \\
(0.98-1.01)\end{array}$ & & \\
\hline Gender (male) & 0.392 & $\begin{array}{c}0.82 \\
(0.52-1.29)\end{array}$ & & \\
\hline Recurrent tumour & 0.791 & $\begin{array}{c}0.94 \\
(0.59-1.50)\end{array}$ & 0.843 & $\begin{array}{c}1.05 \\
(0.64-1.74)\end{array}$ \\
\hline Multiple tumour & 0.102 & $\begin{array}{c}1.45 \\
(0.93-2.26)\end{array}$ & 0.076 & $\begin{array}{c}1.52 \\
(0.96-2.41)\end{array}$ \\
\hline Stage T1 & 0.287 & $\begin{array}{c}1.26 \\
(0.83-1.92)\end{array}$ & 0.146 & $\begin{array}{c}1.46 \\
(0.88-2.43)\end{array}$ \\
\hline Grade 3 & 0.939 & $\begin{array}{c}0.98 \\
(0.63-1.51)\end{array}$ & 0.547 & $\begin{array}{c}1.03 \\
(0.64-1.65)\end{array}$ \\
\hline Concomitant CIS & 0.527 & $\begin{array}{c}0.85 \\
(0.52-1.40)\end{array}$ & 0.797 & $\begin{array}{c}1.08 \\
(0.62-1.88)\end{array}$ \\
\hline $\begin{array}{l}\text { Perioperative } \\
\text { epirubicin }\end{array}$ & 0.155 & $\begin{array}{c}0.73 \\
(0.47-1.13)\end{array}$ & 0.189 & $\begin{array}{c}0.74 \\
(0.47-1.16)\end{array}$ \\
\hline
\end{tabular}

tion of the funnel plot did not demonstrate the asymmetry typically associated with publication bias (Fig. 3b).

\section{Discussion}

To our knowledge, Kaasinen and colleages were the first to suggest the efficacy of immediate instillation in patients who received subsequent BCG therapy. ${ }^{20}$ They retrospectively examined the timing of first mitomycin $C$ (MMC) instillation in patients who received a total of 5 instillations of $\mathrm{MMC}$ followed by BCG or interferon- $\alpha 2 b / B C G$ therapies, using data from a prospective randomized trial. After TUR-BT, 104 patients received the first MMC instillation within 24 hours, and the other 101 received the first MMC on day 1 or later. Subsequent multivariate analysis demonstrated that the timing of the first MMC instillation was an independent significant variable related to recurrence. Receiving the first MMC within 24 hours had a $0.47 \mathrm{HR}(95 \% \mathrm{Cl} 0.32-0.69$, $p<0.01)$ compared to its counterpart. However, in that study, both groups received the combination therapy (chemotherapy plus BCG), which conflicted with our inclusion criteria, and thus it was not included in our cumulative analysis.

To date, 4 prospective randomized trials have compared combination therapy with BCG monotherapy. Cai and colleagues evaluated the impact of one immediate epirubicin instillation preceding the administration of BCG. ${ }^{14}$ They found no statistically significant effect of immediate instillation on recurrence $(p=0.095)$, although the study was underpowered to detect realistic differences in treatment efficacy due to the insufficient number of patients. Cho and colleagues conducted another prospective randomized clinical trial, and for the

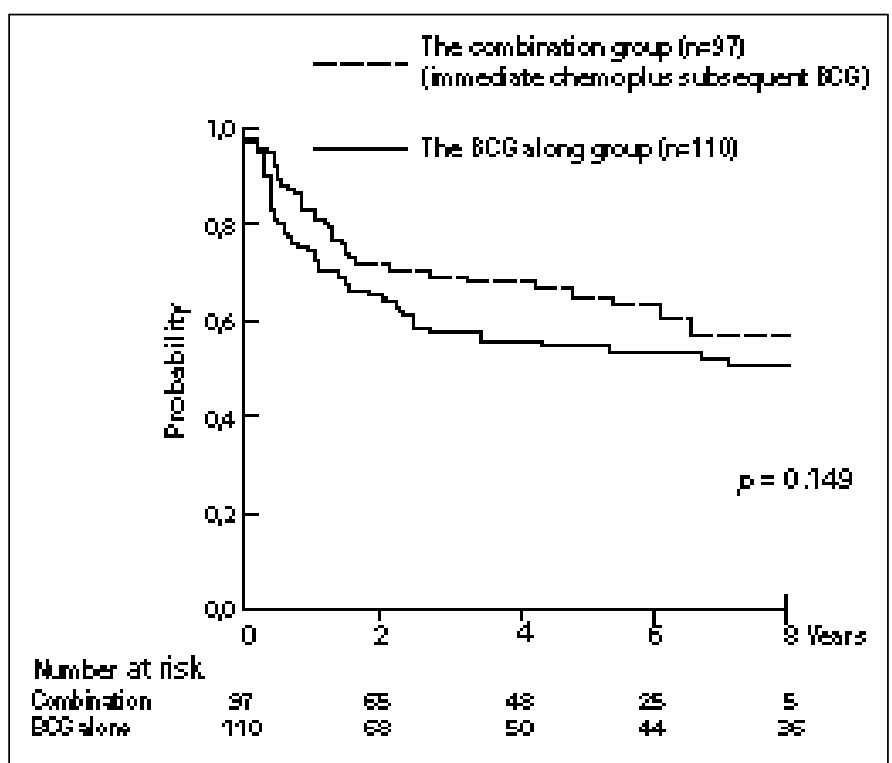

Fig. 1. The Kaplan-Meier curves demonstrated the difference in tumour recurrence-free survival between patients treated with the combination therapy (immediate epirubicin and subsequent bacillus Calmette-Guérin [BCG] therapy) and BCG therapy alone. The time point zero was the timing of the transurethral resection of the bladder tumour.

chemoimmunotherapy group, gemcitabine (GEM) (1000 mg) was instilled immediately after TUR-BT and again (2000 mg) 1 week later. ${ }^{16}$ Kaplan-Meier curves showed that the RFS of patients given GEM plus BCG was higher than that of those on BCG alone, especially in the early phase, although again the difference was not statistically significant.

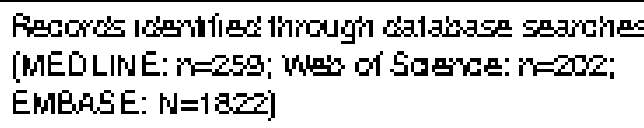

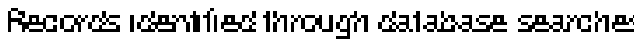
(MEDLINE: $n=253$; Whe of Sagnas: $n=2022$;

EMBASE: $N=1 \mathrm{aZZ}$ ]

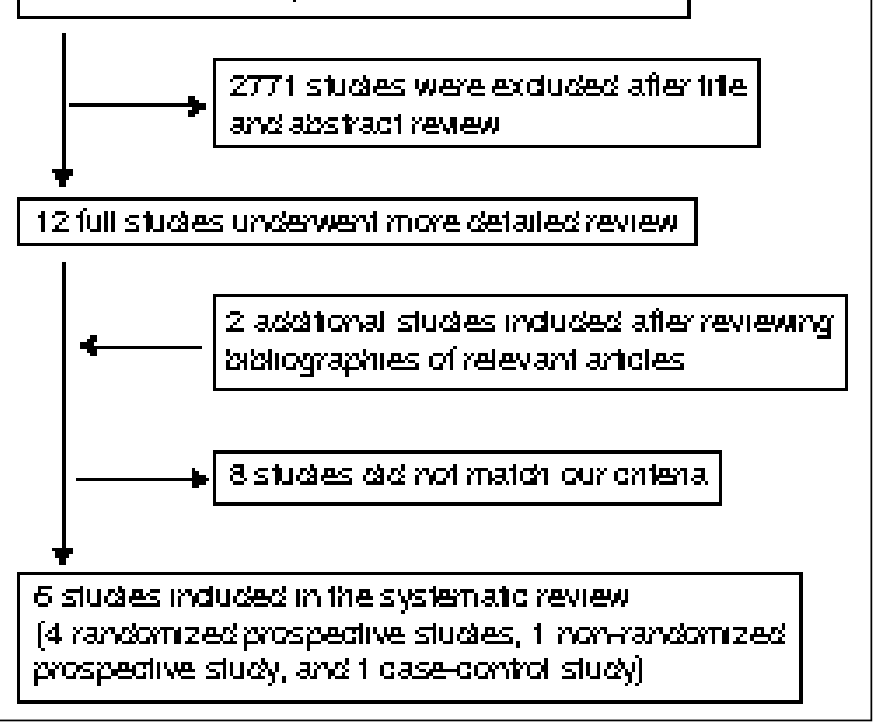

Fig. 2. Flow diagram outlining search results and final included and excluded studies. 
Table 3. Characteristics of reviewed trials

\begin{tabular}{|c|c|c|c|c|c|c|c|c|c|}
\hline \multirow[b]{2}{*}{ Study, year } & \multirow[b]{2}{*}{$\begin{array}{c}\text { Prospective } \\
\text { RCT }\end{array}$} & \multirow[b]{2}{*}{$\begin{array}{l}\text { Inclusion } \\
\text { criteria }\end{array}$} & \multicolumn{2}{|l|}{ Regimen } & \multicolumn{2}{|c|}{ Events/total } & \multicolumn{2}{|c|}{$\begin{array}{l}\text { HR analysis for } \\
\text { RFS }\end{array}$} & \multirow{2}{*}{$\begin{array}{c}\text { RFS compared to } \\
\text { control } \\
\begin{array}{c}\text { (Kaplan-Meier } \\
\text { method) }\end{array}\end{array}$} \\
\hline & & & $\begin{array}{c}\text { Immediate } \\
\text { chemotherapy }\end{array}$ & BCG & $\begin{array}{l}\text { Experimental } \\
\text { (combination) }\end{array}$ & $\begin{array}{c}\text { Control } \\
\text { (BCG alone) }\end{array}$ & $\begin{array}{c}p \\
\text { value }\end{array}$ & $\begin{array}{c}\text { HR } \\
(95 \% \mathrm{Cl})\end{array}$ & \\
\hline Cai, $2008^{14}$ & Yes & $\begin{array}{l}\text { High } \\
\text { (exclude } \\
\text { T1G3) }\end{array}$ & $\begin{array}{c}\text { Epirubicin } 80 \\
\mathrm{mg}\end{array}$ & mBCG & $34 / 80$ & $40 / 81$ & 0.23 & $\begin{array}{c}0.50 \\
(0.32-1.18)\end{array}$ & $\begin{array}{l}\text { Higher } \\
(p=0.10)\end{array}$ \\
\hline $\begin{array}{l}\text { Böhle, } \\
2009^{15}\end{array}$ & No & $\begin{array}{l}\text { All risk } \\
\text { groups }\end{array}$ & GEM $2000 \mathrm{mg}$ & $\begin{array}{c}\text { iBCG } \\
\text { or } \\
\text { mBCG }\end{array}$ & $1 / 13$ & $1 / 21$ & 0.51 & $\begin{array}{c}1.44 \\
(0.49-4.17)\end{array}$ & $\begin{array}{c}\text { Lower (1-year RFS: } \\
62 \% \text { vs. } 79 \% \text { ) }\end{array}$ \\
\hline $\begin{array}{l}\text { Cho, } \\
2009^{16}\end{array}$ & Yes & $\begin{array}{l}\text { Intermediate } \\
\text { and high }\end{array}$ & $\begin{array}{l}\text { GEM } 1000 \mathrm{mg} \\
\text { plus } 2000 \mathrm{mg} \\
\text { (1 week later) }\end{array}$ & ¡BCG & $14 / 36$ & $17 / 51$ & & & $\begin{array}{l}\text { Higher within } 2 \\
\text { years follow-up }\end{array}$ \\
\hline $\begin{array}{l}\text { Abd El } \\
\text { Mohsen, } \\
2010^{17}\end{array}$ & Yes & $\begin{array}{l}\text { Intermediate } \\
\text { and high }\end{array}$ & $\begin{array}{c}\text { MMC } 40 \text { mg } \\
\text { (immediate plus } \\
1,2,3,4 \text { week) }\end{array}$ & mBCG & $9 / 29$ & $16 / 27$ & & & \\
\hline $\begin{array}{l}\text { Badalato, } \\
2011^{18}\end{array}$ & No & $\begin{array}{l}\text { All risk } \\
\text { groups }\end{array}$ & MMC $40 \mathrm{mg}$ & $\begin{array}{c}\text { iBCG } \\
\text { or } \\
\text { mBCG }\end{array}$ & $-/ 48$ & $-/ 212$ & 0.06 & $\begin{array}{c}0.61 \\
(0.36-1.01)\end{array}$ & $\begin{array}{c}\text { Higher } \\
(p=0.02)(5-y e a r \\
\text { RFS: } 56 \% \text { vs. } 38 \%)\end{array}$ \\
\hline $\begin{array}{l}\text { Gülpinar, } \\
2012^{19}\end{array}$ & Yes & $\begin{array}{l}\text { Intermediate } \\
\text { and high }\end{array}$ & MMC $40 \mathrm{mg}$ & ¡BCG & $9 / 25$ & $5 / 26$ & 0.61 & $\begin{array}{c}0.69 \\
(0.45-1.47)\end{array}$ & \\
\hline $\begin{array}{l}\text { Current } \\
\text { study, } \\
2015\end{array}$ & No & $\begin{array}{l}\text { Intermediate } \\
\text { and high }\end{array}$ & $\begin{array}{c}\text { Epirubicin } 80 \\
\text { mg }\end{array}$ & iBCG & $33 / 97$ & $54 / 110$ & 0.19 & $\begin{array}{c}0.74 \\
(0.47-1.16)\end{array}$ & $\begin{array}{c}\text { Higher } \\
(p=0.15)(5-y e a r \\
\text { RFS: } 66 \% \text { vs. } 55 \%)\end{array}$ \\
\hline
\end{tabular}

Abd El Mohsen and colleagues compared the outcomes of patients receiving sequential chemoimmunotherapy (MMC instillation immediately after resection followed by weekly instillation for 4 weeks, and BCG monthly for 1 year) with patients receiving BCG alone (weekly for 6 weeks and then monthly for 1 year) via a randomized prospective study. ${ }^{17}$ They found that tumour recurrence was more frequently observed in patients in the BCG alone group (70\% vs. $31 \%)$. In another prospective randomized trial, Gülpinar and colleagues assigned patients to treatment with perioperative MMC followed by subsequent BCG instillations (once a week for 6 weeks), or treatment with BCG alone. ${ }^{19}$ KaplanMeier analysis demonstrated the similar curves of the two groups, but multivariate analysis, controlling for the other factors, demonstrated that the combination group had a HR of 0.69 (95\% Cl 0.45-1.47). Unfortunately, two of these randomized studies ${ }^{16,17}$ did not report HR data that were valid for inclusion, and our cumulative analysis limited to randomized prospective studies did not reach statistical significance (Fig. 3a).

In another large-scale randomized placebo-controlled trial, the efficacy of a single postoperative instillation of GEM (2 g/100 mL of saline) was examined, and compared to placebo (saline) in terms of RFS. ${ }^{15}$ In that study subsequent BCG therapy after GEM was administered in some eligible patients. Therefore, the results of this subgroup analysis (cases who received subsequent BCG therapy) were included in our cumulative analysis as a non-randomized prospective setting study, and interestingly this is the sole study in our review that demonstrated more than $1.0 \mathrm{HR}$ estimate for the combination therapy $(p=0.51)$. One possible explanation for this negative result was that all patients in both groups received continuous irrigation with saline for at least 20 hours, which might have affected the reduction in tumour recurrence in both and thus masked the efficiency of chemo-instillation. ${ }^{21}$ In another retrospective study, Badalato and colleagues examined the role of immediate MMC prior to an induction course of BCG, and demonstrated that RFS was significantly superior among patients who received the combined therapy (5-year RFS: $56.3 \%$ ) compared to those treated with BCG alone $(37.5 \%, p=0.023) .{ }^{18}$ However, the addition of intravesical therapy prior to BCG did not reach significance as an independent predictor according to multivariate analysis (HR $0.6195 \% \mathrm{Cl} 0.36-1.01, p=0.055$ ).

Most of these previous studies, as well as our single centre study, indicated favourable tendencies of perioperative chemo-instillation prior to BCG in terms of RFS compared to BCG alone, although due to the limited number of patients, each study by itself lacked the power to elucidate statistically the additive value of immediate instillation to subsequent BCG therapy. However, our cumulative analysis enabled us to demonstrate the statistical significance of $\mathrm{HR}$, and suggested that there may be a beneficial effect from using perioperative chemotherapy in those who need BCG therapy.

Our study has several limitations. First, this systematic review included various treatment regimens, using different 


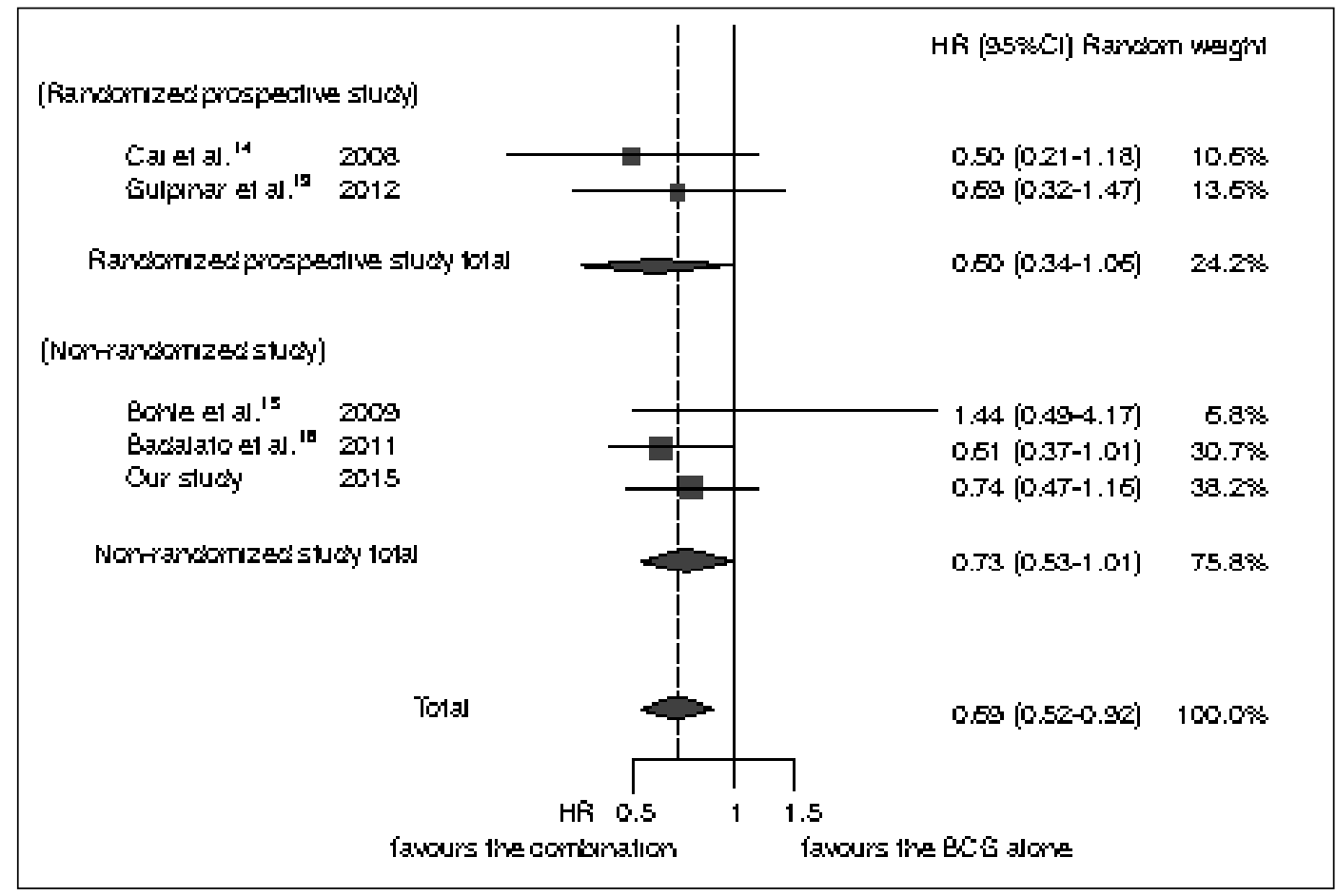

Fig. 3a. Forest plot for recurrence rate. Squares indicate study-specific risk estimates (size of the square reflects the studyspecific statistical weight, i.e., the inverse of the variance); horizontal lines indicate $95 \%$ confidence intervals (CI); diamonds indicate summary risk estimate with its corresponding $95 \% \mathrm{Cl}$.

chemotherapy agents, and doses for immediate instillation. Also subsequent BCG therapy was not conducted according to consistent schedules (induction or maintenance). Additional limitations of this study include the lack of individual patient data, and the likely variation in surgical quality across studies. No patient included in our study cohort received a second TUR, which is increasingly accepted in current clinical practice due to its positive impact, ${ }^{22}$ and this may have limited the generalizability of our results. Meanwhile, most studies reviewed in our cumulative analysis did not specify whether they performed a second TUR or not. Another limitation is that the results of our cumulative analysis were not derived from data from randomized prospective studies only; we included some retrospective data, which limited its evidence level.

\section{Conclusion}

Our analysis suggested that the combination of single chemo-instillation with subsequent BCG therapy exhibited an additive effect against potential tumour recurrence, and single immediate instillation is thus recommended for all NMIBC cases. However, due to the limited quality of evidence, we suggest that a well-designed randomized clinical trial with proper blinding and placebo be performed.

Competing interests: The authors declare no competing financial or personal interests.

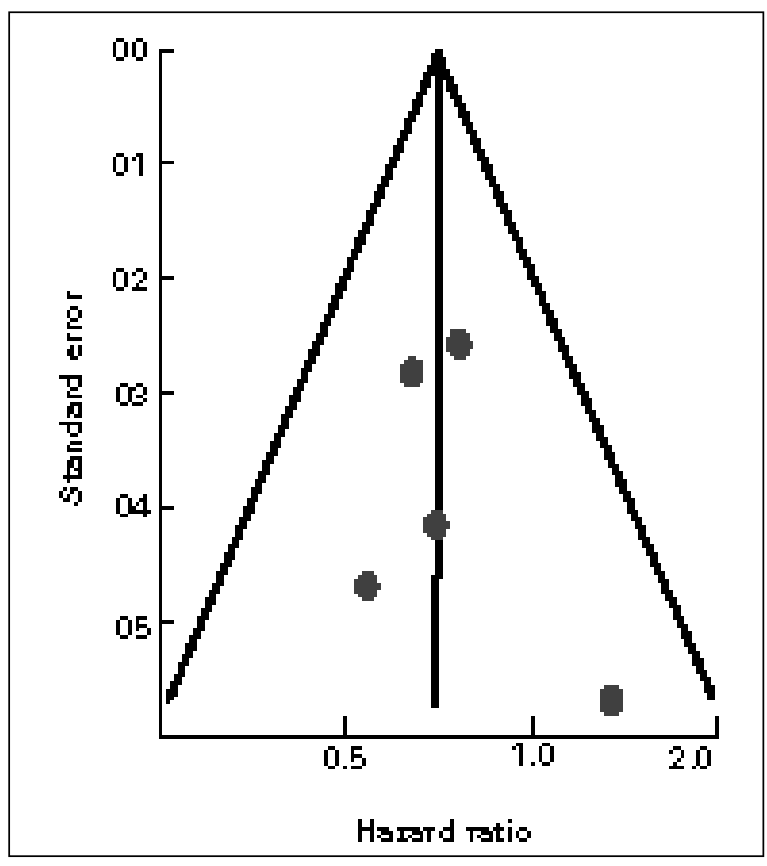

Fig. 3b. Funnel plot examining the possibility of publication bias. The plot was created by comparing the variance with effect size in publications comparing the recurrence-free rate of patients receiving intravesical chemotherapy plus bacillus Calmette-Guérin (BCG) versus $B C G$ alone. 
Matsumoto et al.

This paper has been peer-reviewed.

\section{References}

1. Shelley MD, Kynaston H, Court J, et al. A systematic review of intravesical bacillus Calmette-Guerin plus transurethral resection vs transurethral resection alone in Ta and TI bladder cancer. BJU Int 2001;88:20916. http://dx.doi.org/10.1046/i.1464-410x.2001.02306.x

2. Sylvester RJ, van der Meijden AP, Lamm DL. Intravesical bacillus Calmette-Guerin reduces the risk of progression in patients with superficial bladder cancer: A meta-analysis of the published results of randomized clinical trials. J Urol 2002;168:1964-70. http://dx.doi.org/10.1016/S0022-5347(05)64273-5

3. Böhle A, Jocham D, Bock PR. Intravesical bacillus Calmette-Guerin versus mitomycin C for superficial bladder cancer: A formal meta-analysis of comparative studies on recurrence and toxicity. J Urol 2003; 169:90-5. http://dx.doi.org/10.1016/S0022-5347(05)64043-8

4. Han RF, Pan JG. Can intravesical bacillus Calmette-Guerin reduce recurrence in patients with superficial bladder cancer? A meta-analysis of randomized trials. Urology 2006;67:1216-23. http://dx.doi. org/10.1016/i.urology.2005.12.014

5. Faba OR, Palou J, Breda A, et al. High-risk non-muscle invasive bladder cancer: Update for a better identification and treatment. World J Urol 2012;30:833-40. http://dx.doi.org/10.1007/s00345-012-0967-1

6. Sylvester RJ, Oosterlinck W, van der Meijden AP. A single immediate postoperative instillation of chemotherapy decreases the risk of recurrence in patients with stage Ta TI bladder cancer: A meta-analysis of published results of randomized clinical trials. J Urol 2004;171:2186-90. http://dx.doi.org/10.1097/01. ju.0000125486.92260.b2

7. Palou-Redorta J, Rouprêt $M$, Gallagher JR, et al. The use of immediate postoperative instillations of intravesical chemotherapy after TURBT of NMIBC among European countries. World I Urol 2014;32:525-30. http://dx.doi.org/10.1007/s00345-013-1142-z

8. American Urological Association. Guidelines for the management of nonmuscle invasive bladder cancer (stages Ta,Tl, and Tis): 2007 update. Linthicum, MD: AUA; 2007. https://www.auanet.org/common/ pdf/education/clinical-guidance/Bladder-Cancer.pdf. Accessed June 22, 2015.

9. National Comprehensive Cancer Network. Clinical practice guidelines in oncology: Bladder cancer; 2014.

10. Babjuk $M$, Burger $M$, Zigeuner $R$, et al. EAU Guidelines on non-muscle-invasive urothelial carcinoma of the bladder: Update 2013. Eur Urol 2013;64:639-53. http://dx.doi.org/10.1016/.eururo.2013.06.003

11. DerSimonian R, Laird N. Meta-analysis in clinical trials. Control Clin Trials 1986;7:177-88. http://dx.doi. org/10.1016/0197-2456(86)90046-2

12. Higgins JP, Thompson SG, Deeks JJ, et al. Measuring inconsistency in meta-analyses. BMJ 2003;327:55760. http://dx.doi.org/10.1136/bmi.327.7414.557
13. Egger $M$, Davey Smith $G$, Schneider $M$, et al. Bias in meta-analysis detected by a simple, graphical test. BMJ 1997;315:629-34. http://dx.doi.org/10.1136/bmi.315.7109.629

14. Cai $T$, Nesi $G$, Tinacci $G$, et al. Can early single dose instillation of epirubicin improve bacillus CalmetteGuerin efficacy in patients with nonmuscle invasive high risk bladder cancer? Results from a prospective, randomized, double-blind controlled study. J Urol 2008;180:110-5. http://dx.doi.org/10.1016/i. juro.2008.03.038

15. Böhle A, Leyh $\mathrm{H}$, Frei C, et al; $\mathrm{S} 274$ Study Group. Single postoperative instillation of gemcitabine in patients with non-muscle-invasive transitional cell carcinoma of the bladder: A randomised, double-blind, placebocontrolled phase III multicentre study. Eur Urol 2009;56:495-503. http://dx.doi.org/10.1016/i. eururo.2009.06.010.

16. Cho DY, Bae JH, Moon DG, et al. The effects of intravesical chemoimmunotherapy with gemcitabine and Bacillus Calmette-Guérin in superficial bladder cancer: A preliminary study. J Int Med Res 2009;37:182330. http://dx.doi.org/10.1177/147323000903700618

17. Abd El Mohsen M, Shelbaia A, El Ghobashy S, et al. Sequential chemoimmunotherapy using mitomycin followed by bacillus Calmette-Guerin (MCC + BCG) versus single-agent immunotherapy (BCG) for recurrent superficial bladder tumors. Uro Today Int J 2010;3. http://dx.doi.org/10.3834/uij.19445784.2010 .06 .06

18. Badalato $G M$, Hruby $G$, Razmijo $M$, et al. Maximizing intravesical therapy options: Is there an advantage to the administration of perioperative mitomycin $C$ prior to an induction course of $B C G$ ? Can I Urol 2011:18:5890-5.

19. Gülpinar Ö, Halilioglu AH, Gökçe MI, et al. The value of perioperative mitomycin C instillation in improving subsequent bacillus calmette-guerin instillation efficacy in intermediate and high-risk patients with non-muscle invasive bladder cancer: A prospective randomized study. Int Braz I Urol 2012;38:474-9.

20. Kaasinen E, Rintala E, Hellström $P$, et al; FinnBladder Group. Factors explaining recurrence in patients undergoing chemoimmunotherapy regimens for frequently recurring superficial bladder carcinoma. Eur Urol 2002;42:167-74. http://dx.doi.org/10.1016/S0302-2838(02)00260-9

21. Onishi T, Sasaki T, Hoshina A, et al. Continuous saline bladder irrigation after transurethral resection is a prophylactic treatment choice for non-muscle invasive bladder tumor. Anticancer Res 2011;31:1471-4.

22. Divrik RT, Yildirim U, Zorlu F, et al. The effect of repeat transurethral resection on recurrence and progression rates in patients with $\mathrm{Tl}$ tumours of the bladder who received intravesical mitomycin: A prospective, randomized clinical trial. J Urol 2006;175:1641-4. http://dx.doi.org/10.1016/S0022$5347(05) 01002-5$

Correspondence: Dr. Kazuhiro Matsumoto, Tokyo Saiseikai Central Hospital, Department of Urology, Mita 1-4-17, Minato-ku, Tokyo 108-0073, Japan; kazz_matsumoto@yahoo.co.jp 